\title{
A Study on Reform of Vocal Music Teaching in Colleges and Universities
}

\author{
Feng Liu \\ School of Music \\ Anshan Normal University \\ Anshan, Liaoning, China
}

\begin{abstract}
With the continuous development of society, the teaching of vocal music in colleges and universities must be reformed to meet the needs of the development of the times. The reform of vocal music teaching in colleges and universities should follow the requirements of talents cultivation goal in the new period, get rid of the traditional teaching mode, integrate the elements of autonomous learning of college students, and then realize the training of applied vocal talents, for which this paper makes an analysis on vocal music teaching reform for college students' autonomous learning.
\end{abstract}

Keywords-colleges and universities; college students; autonomous learning; vocal music teaching reform

\section{INTRODUCTION}

At present, in China's vocal education, we more emphasize the training of students' singing skills but pay little attention to the teaching practice, and college students generally lack the awareness and ability of autonomous learning. In the following, we will analyze the application of autonomous learning of college students, sum up the strategy of vocal music teaching reform for college students' autonomous learning.

\section{THE APPLICATION OF AUTONOMOUS LEARNING OF COLLEGE STUDENTS}

\section{A. Autonomous Learning}

In the Western pedagogy theory, autonomous learning is a very important content. Some well-known foreign educationists define the autonomy learning, and they think that the autonomous learning is a mind of learners for their learning content and in the process of learning. In essence, autonomous learning is a critical thinking, which can reflect the independent decision-making ability and the transcendental foresight of students in their autonomous learning. In other words, learners can set up a certain learning objectives, make choice of learning content, determine learning methods, and then build a set of self-assessment system. In the subjective consciousness, the setting of students' learning objectives, the development of learning evaluation, the choice of learning methods and the implementation of learning behavior all are the contents of autonomous learning research. The application of autonomous learning in vocal music teaching can effectively enhance the students' active participation in vocal music teaching activities, so that students can independently explore the important and difficult content in vocal music teaching; at the same time, it can help students find the suitable learning method for them and the helpful materials for their learning, and then achieve a better self-learning effect. In contrast, the traditional passive vocal music teaching has a great limit for the learning efficiency of students, but the autonomous learning can make them gradually improve their learning performance and achieve better learning results.

\section{B. The Role of Autonomous Learning}

In the study of autonomous vocal music, teachers change their role gradually from a single initiator into a comprehensive three-dimensional role, and as a guide, supervisor, judge and counselor, they actively guide the students to make a analysis on their advantage and weaknesses, so as to enhance the comprehensive practical ability of college students, which greatly helps college students make a autonomous learning of vocal music. Moreover, teachers also carry out the evaluation and supervision of the teaching responsibility, to conduct a staged evaluation, provide a fair and objective assessment of learning results of college students, and then point out the shortage of college students in the autonomous learning, and encourage students to actively show their achievement and experience in their autonomous learning of vocal music. In this way, the implementation of autonomous learning is not to entirely deny the role of teachers, nor is to place teachers in a useless situation; in fact, the autonomous learning of colleges students in China, can make teachers better play their leading and guiding role, better achieve the training of students in vocal interest; by these, they can provide a positive valuation of students' learning results and point out the shortage of students in the study, making the role of teachers more clear, and the position and role of teachers more important and specific in teaching activities.

When developing the autonomous learning activities, vocal music teachers should have a clear understanding of students' learning foundation and vocal music literacy, to play a positive guiding role and to ensure students better understand and control their learning advantages and weaknesses; and they should sum up the experience and strategy in vocal music learning, so as to build a effective autonomous learning mechanism of college students. Moreover, teachers' knowledge reserves have some limitations because the vocal music teaching time is limited, just as some education experts say, no matter how hard or responsible teachers are, teaching 
exists limitations. For the unvoiced coherence between teaching and learning, teachers need play a leading role, but also to pay attention to students' self-learning. The vocal music teachers in colleges and universities should strive to cultivate students 'awareness of autonomous learning, broaden students' learning channels, making vocal music teaching obtain more abundant resources. The change of teacher's role has become a key factor for students to carry out autonomous learning, and also an important part of vocal music teaching reform.

\section{The StRATEgIES OF VocAl MUSIC TEACHING REFORM FOR COLLEGE STUDENTS' AUTONOMOUS LEARNING}

\section{A. Make Clear the Objectives of Vocal Music Teaching}

In the reform of vocal music teaching, it is necessary to clarify the objectives of vocal music teaching, to cultivate students' autonomy as one of the important training objectives of vocal music teaching, to understand the actual requirements and purpose of vocal music teaching, to enable students to master the training objectives of vocal music teaching in autonomous learning and to determine their learning objectives through a certain exchange of teachers and students. In the actual autonomous teaching of vocal music, students should take the actual teaching plan as the center and develop their learning objectives according to their actual learning situation, take use of their learning content mastered and know well their learning methods to carry out learning activities, study according to the expected plan, improve learning efficiency, and ultimately complete the learning objectives.

At present, some colleges and universities still use some traditional vocal teaching methods, and teachers use the transferring teaching method (TfT), with little passion in their actual teaching and little interesting in the vocal music teaching, so the actual teaching of vocal music has a bad effect. Teachers should change their teaching concept, make clear the objectives of vocal music teaching in their actual teaching, keep pace with the times, pay great attention to the cultivation of students' autonomous learning ability, teach students in accordance of their aptitude, mobilize students' interest in learning, pertinently develop the teaching in combination with students' practical learning characteristics, apply the modern teaching methods to inspire students' interest in vocal music learning and enhance students' understanding and awareness of vocal music. For the students who have a certain singing foundation, master the certain principle knowledge of voice, resonance and breathing and have the ability to control the degree of breath, such as the students of Grade 1 and 2 of vocal music major of undergraduate education in colleges and universities, teachers can arrange them to focus on the learning of vocal range broadening skills, the promotion of singing skills and the comprehension of singing art of vocal music works in the future study plan. In this way, according to the actual situation of students, make clear students' vocal music learning objectives and make a planned teaching arrangement, so that students can get a systematic vocal culture, carry out autonomous learning step by step, improve their autonomous learning ability and autonomous learning efficiency, so the reform of vocal music teaching in colleges and universities need a clear objective of vocal music teaching.

\section{B. Pay Attention to the Cultivation of Students' Singing Aesthetics}

Vocal music is a discipline of practical type, and for teachers and students, it is abstract and subjective. For students, the cultivation of students' singing aesthetics is to make students conduct effective vocal music learning. In the singing, the students of vocal music will be largely affected by the aesthetic standard of singing, so it is very important to cultivate students' singing aesthetics and to carry out autonomous vocal learning. Teachers also help students to establish a good sound aesthetics, to cultivate a good singing aesthetic awareness of students. For the beginners of vocal music, we can play some video or audio of vocal music of different types for them, let them see some audio and video information and feel the characteristics of vocal music works of different types. After a long-term training, students can achieve the formation of more intuitive sound model, and then have a specific concept of sound. For a long time, the objectives of vocal music teaching reform will be achieved continuously, and students can accumulate a wealth of auditory experience, have the ability to accurately determine the sound of various types, master the professional sound technology and get the ability of artistic processing.

In addition, we must pay attention to cultivation of students' innovative consciousness. Students' moral quality is to consciously abide by the socialist core values in the daily life, and we should cultivate students' good habits. Vocal music teaching can develop students 'minds, promote students' intellectual growth, and help students improve their appreciation level and aesthetic level, effectively cultivate students' lofty sentiments, inspire students' enterprising spirit and improve students' comprehensive qualities. In order to cultivate students' singing and aesthetic ability, we need to pay attention to inspiration of students' innovation consciousness, so that students can make their self-cultivation and selfshaping of singing aesthetics under the influence of innovation consciousness, and students also further promote their leaning enthusiasm and initiative for vocal music. Teachers can carry out a variety of rich and colorful vocal music teaching activities to train students' innovative thinking ability and to achieve the purpose of cultivating students' singing aesthetics, e.g. playing various types of vocal works for students, cultivating students' aesthetics of different arts, respecting for the aesthetic needs of students and cultivating student's aesthetics of different singing. Through vivid vocal music teaching activities, we can effectively increase the students' ability of learning and innovative thinking, which will help to enhance students' aesthetic sense of singing and improve students' aesthetic ability of singing.

\section{Enhance Students' Ability of Singing Performance}

Vocal music is a subject with obvious comprehensive characteristics. Teachers can develop the inspection and learning of vocal music, and held concerts, etc. to exercise students' ability of singing. Through the activities of various types, we can effectively examine the students' actual vocal music learning, develop good on-stage singing psychology of students; promote students' healthy competition, help students overcome the scare of on-stage singing. In the actual 
autonomous learning of vocal music, we can carry out the practical training for three or four times each semester, such as concerts, inspection and learning activities of singing, etc., with teachers providing guidance and evaluation on the spot. If colleges have good resources conditions of vocal music, students can record the concert by themselves, for their repeated watching; to understand the on-stage singing skills and the advantages and disadvantages in vocal performance, to encourage students to complete the objectives of vocal music learning, improve students' comprehensive ability to find, analyze and solve problems of vocal music.

For some colleges and universities with bad conditions, teachers can organize students to carry out some scene singing, and through the scene creation of vocal music teaching, inspire students' enthusiasm, so as to improve the appreciation level of students in the daily teaching and train students' comprehensive singing ability. In the actual vocal music teaching, the vocal music teaching scene created by teachers should coincide with the students 'actual learning situation, to enhance students' interest in vocal music learning and help students learn vocal music better. For example, when explaining the knowledge of vocal music, teachers can try to let students understand the knowledge of vocal music, so that students can get better comprehension of vocal music under the guidance of existing knowledge, and when having some incomprehensible problems, they can put forward them and make exchange with other students or teachers to solve the problems. In the demonstration of singing, teachers can let students attempt practice according to the textbook, promoting students' experience for the charm of vocal music. In the teaching, teachers should keep free and easy gestures and relaxed language, so that students study vocal music in a pleasant environment, which can make students carefully experience the wonderful vocal art and feel the unique characteristics of vocal art. Of course, in the setting of teaching scene, teachers can combine with students' life and the natural things and blend with students' style of daily life, to inspire students' emotional recognition, to make students appreciate and experience the value of vocal art with their inner feeling, and then to enhance the students' ability of singing, so students' ability of sing should be enhanced in the reform of vocal music teaching.

\section{CONCLUSION}

The reform of vocal music teaching for college students' autonomous learning should also be combined with the teaching experience in the colleges and universities, so we should study modern educational technology, master the advanced educational idea, pay attention to the students' ability of autonomous learning, to finally realize the objectives of vocal music teaching and achieve the reform of vocal music teaching in colleges and universities.

\section{REFERENCES}

[1] Liao Xinglin. Research on Vocal Music Teaching Reform based on College Students' Autonomous Learning [J]. Yellow River's Voice, 2016,12: 22-23
[2] Gao Jing, Li Shujuan. The Application of Research Study in Vocal Music Teaching in Normal University [J]. Education and Occupation, 2012,03: 127-128.

[3] Liao Xinglin. The Exploration and Practice of Flipped Classroom Teaching Mode of Vocal Music in Colleges and Universities [J]. Home of Theater, 2015,17: 181-182.

[4] Lin Lin. The Evaluation and Analysis on "Peer-assisted Learning" in College Teachers' Vocal Music Teaching [J]. Journal of Suzhou University, 2010,2512: 120-123. 